\title{
A decision analysis model for elective neck dissection in patients with cT1-2 cN0 oral squamous cell carcinoma
}

\author{
Proposta di un modello analitico-decisionale per lo svuotamento laterocervicale \\ nei pazienti affetti da carcinoma squamocellulare del cavo orale cT1-2 cNO
}

H.F. KÖHLER, L.P. KOWALSKI

Department of Head and Neck Surgery and Otolaryngology, AC Camargo Cancer Center, São Paulo, Brazil

\begin{abstract}
SUMMARY
Neck metastasis from oral squamous cell carcinoma (OSCC) has a significant impact on disease-specific and overall survival. Physical examination and imaging exams are used to stage the neck, but preoperative neck staging cannot reliably differentiate between metastatic and non-metastatic nodes. The decision to perform elective neck dissection (END) should consider the probability of neck metastasis and the harm of unnecessary surgery. We evaluate if this model can be used to decide treatment and the net benefit with different strategies. We reviewed patients treated from January, 1985 to December, 2012. Inclusion criteria were histological diagnosis of OSCC, initial surgery and primary tumour in the oral cavity staged as cT1-2 cN0. Development of a predictive model for metastatic nodes used patients submitted to END. The probability of neck metastasis was calculated and decision curve analysis was performed. We considered two interventions: watchful waiting and END, and two outcomes, regional recurrence and disease-free survival. We developed the model using logistic regression after multiple inputs with neck metastasis as an outcome. The initial model included all demographic and pathological variables. This model has an area under the curve (AUC) of 0.8423 , a positive predictive value (PPV) of $70.7 \%$ and a negative predictive value (NPV) of $80.2 \%$. We used LASSO for coefficient reduction and variable selection. This model has an AUC of 0.8265 with PPV of $68.3 \%$ and NPV of $80.2 \%$. For neck recurrence, the curves of "treat all by watchful waiting" and "treat none by watchful waiting" crossed at the prevalence of neck metastasis. When focusing on disease-free survival, the decision analysis curve shows a pattern where the predictive model provides a net benefit if used to choose treatment from a $20 \%$ until a $54 \%$ threshold.
\end{abstract}

KEY WORDS: Oral cancer • Neck dissection • Decision models

\section{RIASSUNTO}

Le metastasi laterocervicali da carcinoma squamocellulare del cavo orale (OSCC), hanno un impatto significativo sulla sopravvivenza malattia specifica e sulla sopravvivenza globale. L'esame clinico e la radiologia sono utilizzate per stadiare il collo, ma la stadiazione preoperatoria non può efficacemente differenziare i linfonodi metastatici da quelli non metastatici. La decisione di eseguire lo svuotamento del collo deve considerare la probabilità di metastasi laterocervicali e il rischio di una chirurgia non necessaria. Abbiamo valutato se questo modello può essere usato per la decisione del trattamento e quale è il beneficio netto con le singole strategie. Abbiamo revisionato i pazienti trattati dal Gennaio 1985 al Dicembre 2012. I criteri di inclusione sono stati: diagnosi istologica di OSCC, chirurgia iniziale e tumore primitivo del cavo orale stadiato come cT1 T2 NO. Abbiamo sviluppato un modello predittivo per $i$ linfonodi metastatici usando $i$ pazienti sottoposti a dissezione del collo. La probabilità di metastasi laterocervicale è stata calcolata ed è stata eseguita un' analisi della curva decisionale. Abbiamo considerato due tipologie di comportamento: attesa vigile e dissezione del collo e due outcome: recidiva regionale e sopravvivenza libera da malattia. Abbiamo sviluppato il modello usando una regressione logistica dopo multipli imput utilizzando le metastasi laterocervicali come un outcome. Il modello iniziale includeva tutte le variabili patologiche e demografiche. Questo modello ha un AUC di 0,8423, un PPV del 70,7\% e un NPV dell'80,2\%. Abbiamo usato LASSO per coefficiente di riduzione e selezione variabile. Questo modello ha un AUC dello 0,8265 con un PPV del 68,3\% e NPV dell'80,2\%. Per le recidive sul collo, le curve di "trattati tutti con attesa vigile" e "nessuno trattato con attesa vigile" si incrociavano alla prevalenza delle metastasi laterocervicali. Concentrandoci sulla sopravvivenza libera da malattia, la curva di analisi decisionale mostrava un pattern dove il modello predittivo forniva un netto beneficio se usato per scegliere il trattamento fra un limite del $20 \%$ fino al $40 \%$.

PAROLE CHIAVE: Carcinoma del cavo orale $\bullet$ Dissezione del collo $\bullet$ Modelli di decisione 


\section{Introduction}

Neck metastasis from oral squamous cell carcinoma (OSCC) is a major prognostic variable with a significant impact in disease-specific and overall survival, and the presence is considered as an indication for adjuvant treatment ${ }^{1}$. In patients with OSCC, physical examination and imaging exams are used to stage the neck, but all have limitations since they rely on morphological characteristics of the lymph node to differentiate free and metastatic nodes ${ }^{2}$. In a recent report, neck metastases were found in $44 \%$ of patients staged as cN0 following physical examination and CT-scan ${ }^{3}$. This is a reflection of two limitations of imaging methods that must be considered. The first is the usual trade-off between specificity and sensitivity. More stringent criteria increase sensitivity on the expense of specificity and the converse is also true. The second limitation reflects that while sensitivity and specificity are an intrinsic property of the method, predictive values are not. The use of even high sensitivity and specificity methods in low prevalence settings may decrease its diagnostic value ${ }^{4}$. Therefore, preoperative neck staging is limited and cannot reliably differentiate between metastatic and non-metastatic nodes.

While there is a general consensus that patients with cT3 and cT4 cN0 primary OSCC or clinically-evident node metastasis should have their necks treated, no consensus exists on patients with early-stage OSCC and negative necks. In an article reviewing the neck treatment options of American otolaryngologists, a significant variation in the performance of END was shown according to physician's volume, and a significant percentage (10\%) would adopt watchful waiting in all situations ${ }^{5}$. A similar trend was found in Germany where no uniform treatment choice of the neck was found for primary tumours of multiple head and neck sites, including those of the oral tongue and floor of mouth ${ }^{6}$. The lack of uniformity in treatment choice may reflect the lack of consistent evidence favouring END over watchful waiting in the literature. Five prospective randomised trials have been performed to address this issue, but all suffer from small sample size and the reported results are contradictory. Three showed no clear benefit of END in disease-specific survival ${ }^{7-9}$, but the remaining two showed significant improvement for patients submitted to END ${ }^{1011}$. A recent and growing trend is the use of sentinel node biopsy, but trials have compared their results to END and not to watchful waiting ${ }^{12}$.

In an attempt to address this question, two decision analysis models were designed. The first was published by Weiss et al. and based on several assumptions using data from the literature then available. He considered the utility of treatment as a variable ranging from 0 to 1 and considered the incidence of occult neck metastasis, treat- ment complications and disease-specific survival ${ }^{13}$. The second is more recent and utilises the same methodology, using both values derived from the first and from the authors' own experience ${ }^{14}$. A significant drawback of both publications is that although they state a threshold for occult neck metastasis, neither states how this probability is calculated. Therefore, they rely mainly on theoretical assumptions based on "what if" scenarios. Also, all trials and models were performed before the incorporation of depth of invasion in the staging system for OSCC ${ }^{15}$.

To decide whether an END should be performed, we must consider the probability of neck metastasis for a given individual. If this probability is high enough, treatment should be administered, while, otherwise, no treatment should be instituted. However, it must also be remembered that harm may be caused to an individual who receives treatment without the disease. Our objective in this study is to evaluate if this model can be used to decide the need for END and the net benefit with different neck treatment strategies. We chose to adopt a different modelling strategy, relying on a decision curve analysis instead of a decision tree. A major advantage is the capability of the clinical curve to translate predictive models into clinically useful information ${ }^{16}$.

\section{Materials and methods}

We retrospectively reviewed 207 patients treated in a single institution from January 1985 to December 2012. Inclusion criteria were histological diagnosis of squamous cell carcinoma, initial treatment by surgery (with or without elective neck dissection), primary tumour located in the oral tongue, inferior gingival rim or floor of mouth and staged as cT1 or cT2 and neck staged as cN0 after physical and radiological examinations. In all patients, radiological examination consisted of CT scan or MRI. We excluded patients with previous treatment or excisional biopsy of the primary tumour or cervical lymph nodes, second primary tumours and neck staging by physical examination alone. Data was collected using a standard form concerning demographic, clinical and treatment-related variables. The neck dissection specimen was analysed by the pathologist and each lymph node was submitted to histologic examination after standard tissue processing with 5 micrometre sections and haematoxylin and eosin staining. Based on data from clinical charts and pathologic reports, tumour staging was updated to the current standard ${ }^{15}$.

Statistical analysis was performed using the Stata software package. We described continuous variables using mean and standard deviation (SD) and categorical variables using frequencies. We compared the proportion of patients with metastatic nodes considering the different 
categorical variables. For tumour thickness and size, a ttest was used. All tests were considered bicaudal. Missing values were filled in using multiple imputation by chained equations (MICE) with ten repetitions. Multiple imputation (MI) replaces missing values with multiple sites to complete the data, applying the standard statistical analysis for each dataset and adjusting the parameters for missing data uncertainty. By including only subjects with complete data at a given analysis, there is an increased potential for bias introduction and a loss of precision and power. The outcome of interest, age, sex, cT stage and adjuvant radiotherapy were included in the imputation procedure. We further validated the MI by comparing the results with and without this procedure ${ }^{17}$.

The development of a predictive model for metastatic nodes used only those patients submitted to synchronous neck dissection. Neck staging was treated as a binary variable (non-metastatic versus metastatic). Logistic regression was used to generate a linear predictor. A LASSO algorithm ${ }^{18}$ was used for coefficient shrinkage and variable selection. For both models, a receiver operating characteristic (ROC) curve was drawn, the area under the curve (AUC) calculated and classification statistics obtained. The ROC curve plots the sensitivity against the false-positive rate and allows visualisation of test performance. Based on this score, we calculated the probability of occult neck metastasis and developed a decision curve analysis ${ }^{16}$. We considered two different interventions: watchful waiting and END, and two different outcomes, regional recurrence and disease-free survival.

This study was approved by the Internal Committee on Research Ethics.

\section{Results}

For the predictive model of occult neck metastasis, we included 207 consecutive patients. There were 164 males (79.2\%) and 43 females (20.8\%). Age ranged from 21 to 87 years (mean 57.4 years, and SD, 12.5 years). There were 164 patients $(79.2 \%)$ staged as $\mathrm{T} 1$ and 43 patients $(20.8 \%)$ staged as cT2. Ipsilateral neck dissection was performed in all patients with 103 cases $(49.8 \%)$ of selective neck dissection (levels I-III) and 104 cases (50.2\%) of modified radical neck dissection. Contralateral neck dissection was performed in 22 patients $(10.63 \%)$ with 2 cases $(9.1 \%)$ of modified radical neck dissection and 20 cases $(90.9 \%)$ of selective neck dissection (levels I-III). The indication for contralateral neck dissection was a primary tumour crossing or located in the midline. Vascular invasion was present in 56 patients $(27.05 \%)$ and neural infiltration in 66 patients $(31.88 \%) .126$ patients had well differentiated tumours, 65 patients $(31.40 \%)$ had moderately differentiated tumours and 13 had poorly differentiated tumours $(6.28 \%)$. There were 150 patients $(72.5 \%)$ with negative necks ( $\mathrm{pN} 0)$ and 57 patients $(27.5 \%)$ with metastatic nodes $(\mathrm{pN}+)$. The number of dissected nodes ranged from 6 to 116 in the ipsilateral neck (median, 36 nodes) and from 4 to 44 in the contralateral neck (median, 26 lymph nodes). The number of metastatic nodes in the ipsilateral neck ranged from 0 to 7 and in the contralateral neck from 0 to 2 .

We developed the model using a logistic regression before and after multiple imputation with the presence of neck metastasis as outcome of interest. The initial model included all demographic and pathological variables. A significant difference in the effect of tumour thickness was noted in different tumour sizes and an interaction term of both variables was included. This model has an AUC of 0.8423 , a positive predictive value (PPV) of $70.73 \%$ and a negative predictive value of $80.22 \%$, classifying correctly $77.27 \%$ of all patients. We performed a bootstrap with 2,000 replications to assess the model optimism and determined new coefficients and intercept with an AUC of 0.8328. Finally, we used LASSO to perform coefficient reduction and variable selection. This model has an AUC of 0.8265 with PPV of $68.29 \%$ and NPV of $80.18 \%$, correctly classifying $76.97 \%$ of patients when applied at the original series (Fig. 1). The coefficients and constant for each model are displayed in Table I.

The decision analysis was based on 318 consecutive patients with cT1-2 cN0 OSCC. There were 235 males $(73.9 \%)$ and 83 females (26.1\%). Age ranged from 21 to 85 years (mean 58.5 years and SD, 12.6 years). There were 131 patients staged as cT1 $(41.2 \%)$ and 187 patients as cT2 $(58.8 \%)$. The primary tumour was resected in all patients; 111 patients $(34.9 \%)$ were treated by watchful

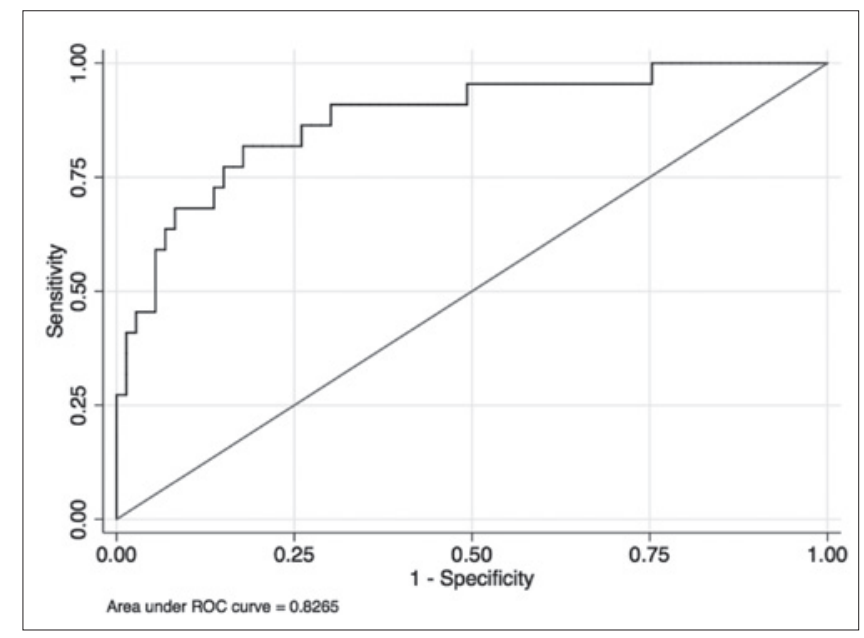

Fig. 1. ROC curve of the logistic regression for prediction of occult lymph node metastasis after LASSO adjustment. 
Table I. Coefficients and constants of the initial model with and without multiple imputation, after bootstrap and after LASSO.

\begin{tabular}{lcccc} 
Variable & Initial model & Initial model MI & Bootstrap & LASSO \\
Age & -0.0563 & -0.0415 & -0.0405 & 0.0038 \\
Gender & 1.1932 & 1.0660 & 0.8681 & 0.1453 \\
Tumour thickness & 0.4044 & 0.3738 & 0.0383 & 0.1255 \\
Tumour diameter & 2.1556 & 2.2583 & 0.3106 & 0.1255 \\
Vascular invasion & 2.5057 & 2.3603 & 2.3603 & 0.3645 \\
Neural invasion & 0.1664 & 0.1643 & 0.1561 & 0.0049 \\
Histological grade & 1.2261 & 1.1281 & 0.9888 & 0.1682 \\
Thickness\#diameter $\left(^{*}\right)$ & -0.1431 & -0.1767 & 0.0477 & 0.0120 \\
Constant term & -5.2627 & -6.6353 & -3.3467 & 1.4734 \\
\hline
\end{tabular}

$\left.{ }^{*}{ }^{\star}\right)$ Thickness\#diameter represents the interaction term between the two variables.

waiting while 207 patients $(65.1 \%)$ were submitted to elective neck dissection. In patients submitted to END, the number of dissected nodes ranged from 6 to 116 . Occult neck metastases were found in 57 patients with the number of metastatic nodes ranging from 1 to 7 . Pathological neck staging was pN0 in 150 patients (72.5\%), $\mathrm{pN} 1$ in 31 patients $(15.0 \%), \mathrm{pN} 2 \mathrm{~b}$ in 23 patients and $\mathrm{pN} 2 \mathrm{c}$ in 3 patients. Extracapsular spread was diagnosed in 12 patients submitted to END. The demographic and pathological characteristics are described in Table II.

The median time of follow-up was 54.4 months (range, 8.1 to 156.3 months). There were 43 cases $(13.5 \%)$ of neck recurrence during follow-up, but in nine patients these were associated with synchronous local recurrence and in only 34 cases $(10.7 \%)$ the neck was the single recurrence site. Nineteen isolated neck recurrences occurred in patients submitted to watchful waiting and 15 cases in patients treated by END. In univariate survival analysis using neck recurrence as outcome of interest, only END was associated with an improved regional control (HR: 0.444, 95\% CI: 0.225 - 0.875, $\mathrm{p}=0.019$, Fig. 2). Salvage was successful in 12 of 19 patients in the watchful waiting group and in 5 of 15 patients in the END group. There were 17 deaths due to disease progression in patients with isolated neck recurrence; 10 in the END group and 7 in the watchful waiting group. Elective neck treatment was associated with disease-specific survival (HR: 1.635, 95\% CI: 0.927 - 2.884, p = 0.089, Fig. 3).

The decision curve model allows for definition of outcome and harm associated with the procedure. Neck recurrences and disease-free survival were the outcomes of interest in our analysis. In our series, there were 5 cases $(2.4 \%)$ of salivary fistula and 2 cases $(1.0 \%)$ of lymphatic fistula after END. On a report analysing morbidity after END, the complication rate was $4 \%$ corresponding to two lymphatic fistulas and subjective analysis of body movement by the patients disclosed no restrictions in $96.2 \%$ of them ${ }^{19}$. Based on these data, we set the harm of END at $4.0 \%$.

For neck recurrence, the curves of "treat all by watchful waiting" and "treat none by watchful waiting" as well as the model crossed at the prevalence of neck metastasis (Fig. 4). In this situation, a very low threshold for neck dissection is advocated, with a net benefit approaching zero at a threshold of $20 \%$.

Table II. Demographic and pathological characteristics of patients included in the decision model analysis according to neck treatment modality.

\begin{tabular}{|c|c|c|c|c|}
\hline Variable & Values & Observation group & ND group & \\
\hline Gender & $\begin{array}{l}\text { Male } \\
\text { Female }\end{array}$ & $\begin{array}{l}71 \\
40\end{array}$ & $\begin{array}{c}164 \\
43\end{array}$ & 0.003 \\
\hline Age (years) & Mean and SD & $60.53 \mathrm{SD}, 12.54$ & 57.43 SD, 12.45 & 0.035 \\
\hline cT stage & $\begin{array}{l}\text { cT1 } \\
\text { cT2 }\end{array}$ & $\begin{array}{l}84 \\
27\end{array}$ & $\begin{array}{c}47 \\
160\end{array}$ & $<0.001$ \\
\hline Vascular invasion & $\begin{array}{c}\text { No } \\
\text { Yes } \\
\text { Missing }\end{array}$ & $\begin{array}{c}96 \\
9 \\
6\end{array}$ & $\begin{array}{c}139 \\
61 \\
7\end{array}$ & $<0.001$ \\
\hline Differentiation & $\begin{array}{c}\text { Well } \\
\text { Moderate } \\
\text { Poor }\end{array}$ & $\begin{array}{c}82 \\
25 \\
4\end{array}$ & $\begin{array}{c}126 \\
65 \\
16\end{array}$ & \\
\hline Tumour thickness (mm) & Mean and SD & 3.846 SD, 2.763 & 7.289, SD 4.969 & $<0.001$ \\
\hline Tumour size (mm) & Mean and SD & 9.620 SD, 3.836 & 26.497 SD 8.935 & $<0.001$ \\
\hline
\end{tabular}




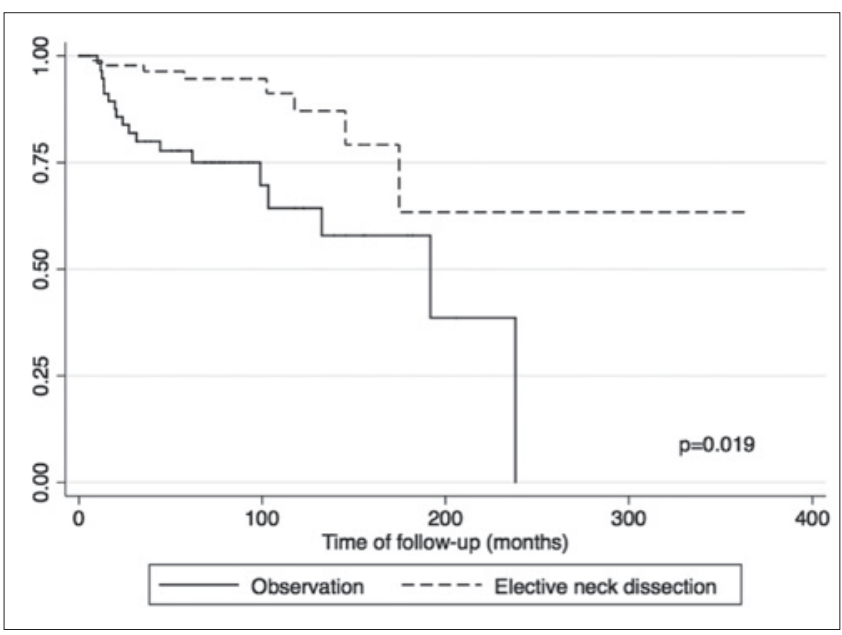

Fig. 2. Kaplan-Meier graph of neck recurrence as the outcome of interest in patients submitted to END or observation.

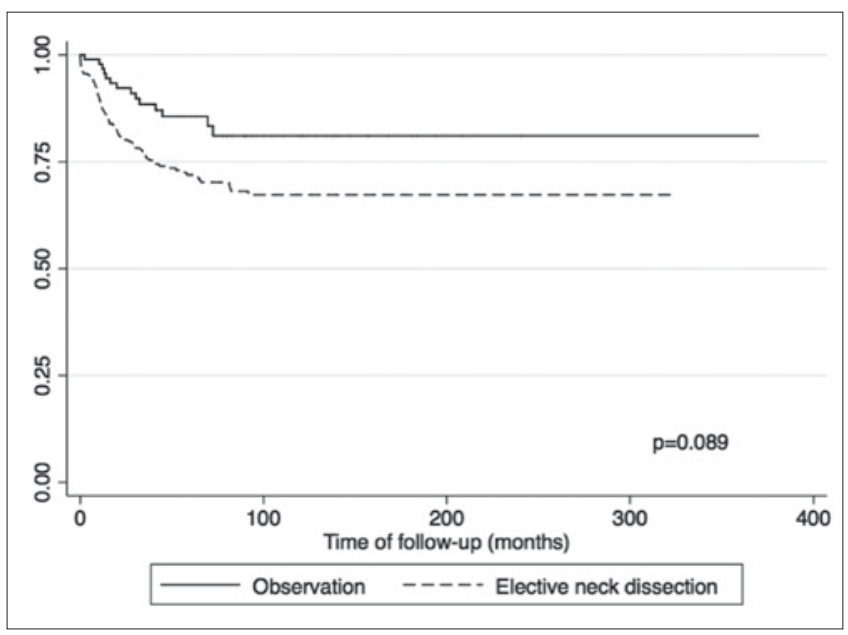

Fig. 3. Kaplan-Meier graph of disease-specific survival in patients submitted to END or observation.

When we focused on disease-free survival, the decision analysis curve shows a pattern where "treat all by watchful waiting" and "treat none by watchful waiting" cross at the prevalence of neck metastasis but the predictive model provides a net benefit if used to choose treatment from a $20 \%$ until a $54 \%$ threshold (Fig. 5). Below the $20 \%$ threshold, the treat all by observation is the most adequate, while above $54 \%$ the END is beneficial. The net benefit of the model is seen in Table III. The table can be interpreted using an example. If we chose a threshold of $30 \%$ and acted according to prediction, we could spare END in 3.8 patients from each 100 treated patients without leaving a true positive patient untreated. We must remember that the use of predictors in decision curve are related to their diagnostic properties. Therefore, a sensitive predictor is better than a more specific

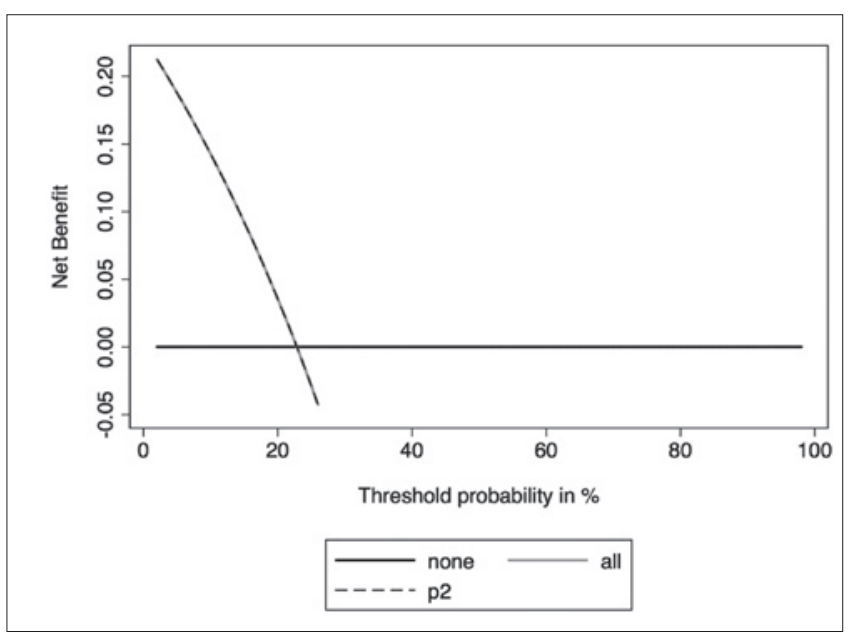

Fig. 4. Decision curve for END using neck recurrence as the outcome of interest. The lines cross at the occult neck metastasis prevalence, advocating for END a low threshold for elective neck dissection treatment.

predictor if the hazard associated with a false-negative result is greater than the hazard of a false-positive result, as is in this situation.

\section{Discussion}

The objective of OSCC treatment is to maximise survival while decreasing morbidity. One way to accomplish this is to define risk groups and adopt different treatment strategies for each group. This would allow for more personalised care while retaining oncologic safety and improving survival and quality of life.

Nowadays, evidence-based medicine is regarded as best

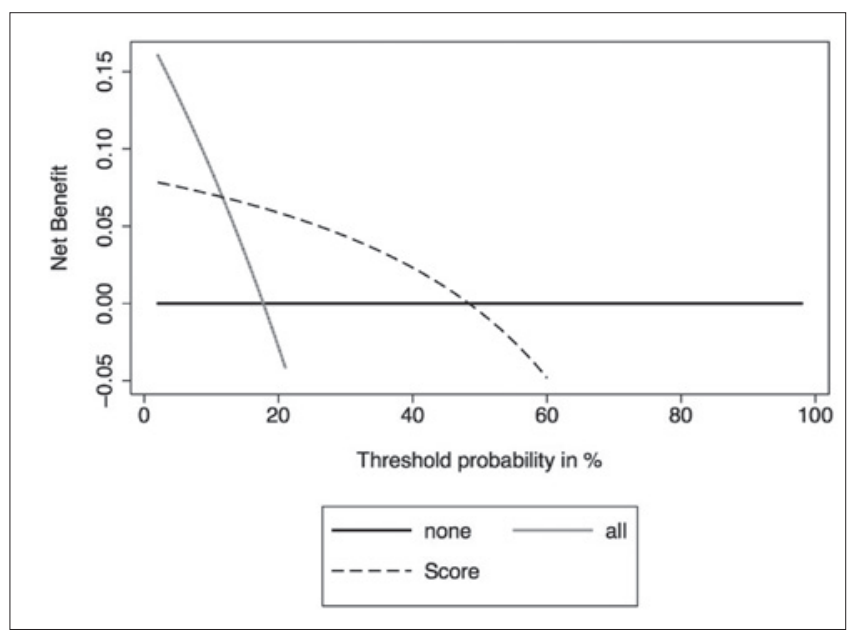

Fig. 5. Decision curve for END using disease-specific survival as outcome of interest. There is a significant difference from the previous curve with the use of the predictive model being preferred in patients with intermediate (20 to $54 \%$ ) risk of occult neck metastasis. 
Table III. Net benefit considering different threshold for neck metastasis probability and the decision to treat all patients by elective neck dissection or according to decision model.

\begin{tabular}{lcc} 
Threshold & Treat all & Model \\
2 & 0.199968144 & 0.124976831 \\
5 & 0.174703985 & 0.112431312 \\
10 & 0.128854215 & 0.106626481 \\
15 & 0.077610336 & 0.100491672 \\
20 & 0.019960985 & 0.09696501 \\
21 & 0.007555427 & 0.096206109 \\
22 & -0.005168221 & 0.092427751 \\
23 & -0.018222354 & 0.089629171 \\
24 & -0.031620014 & 0.086809578 \\
25 & -0.045374949 & 0.084968132 \\
35 & & 0.066129651 \\
45 & & 0.057713545 \\
50 & & 0.032993076 \\
54 & & 0.012651758 \\
\hline
\end{tabular}

practice, but in some cases its usefulness is limited. In the analysis of END for cT1-2 cN0 OSCC, we found just such a situation. The results of the five prospective randomised trials are contradictory ${ }^{7-11}$. We must also consider that in the three of these routine preoperative evaluation was performed by physical examination alone, which has limitations in the diagnosis of neck metastasis ${ }^{9}$. In the current setting, routine use of imaging methods is considered mandatory, but they have a limited ability to detect neck metastasis. In a prospective study with 166 OSCC patients using PET, CT scan, MRI and USG, no method had an accuracy over $76 \%$. PET had the best specificity at $82 \%$, while US had the best sensitivity at $84 \%{ }^{20}$. In a recent meta-analysis including only patients with clinically negative necks, CT scan, MRI, USG and PET were compared. The sensibility ranged from $52 \%$ to $\mathrm{CT}$ scan to $66 \%$ to MRI and US, while the specificity ranged from $7 \%$ to US to $93 \%$ to CT scan. The Quality Assessment of Diagnostic Accuracy Studies were not different between the different modalities ${ }^{21}$. An imaging method that holds promise is contrast-enhanced colour Doppler sonography. In a series of 39 patients, peripheral vessels were indicative of metastasis with a sensitivity of $100 \%$ and specificity of $98 \%{ }^{22}$. When trying to quantify the abnormal findings by this method, difficulties were found due to a significant overlap of benign and malignant features in a small series of 28 patients ${ }^{23}$. These conflicting results are related to a major issue raised by sonographic images: the high dependence on the operator. However, the results shown in the initial series hold promise to this technique.

The previously described decision analysis models were based on theoretical assumptions derived from two different moments in the literature. The report by Weiss et al. ${ }^{13}$ relies on information collected from articles during the 80 's and early 90's, while the one from Okura et al. ${ }^{14}$ relies on publications from the 2000's. This difference may explain their different thresholds. However, the incidence of neck metastasis as a significant variable for deciding on END finds support in the literature. END provided a significant survival advantage over observation in a recent report analysing the impact of perineural invasion (PNI) in prognosis. In this series, PNI was also highly significant for occult neck metastasis ${ }^{24}$. Conversely, in patients with early stage OSCC and no risk factors, END and observation have comparable results regarding both disease-specific survival and regional control ${ }^{25}$. In disagreement with the threshold proposed by Weiss et al., a retrospective analysis of a cohort of patients with stage I OSCC showed no significant difference in survival and regional control between END and observation although their occult metastasis rate was $23.7 \%{ }^{26}$. A similar finding was reported recently in a study of cT1 cN0 OSCC with an occult neck metastasis rate of $23 \%$, but no difference between END and observation in regional disease control ${ }^{27}$. In a recent meta-analysis of 23 articles comparing END and observation, initial approach with END resulted in improved regional recurrence rate and disease-specific survival but not overall survival ${ }^{28}$. A major limitation of all these reports is the use of staging systems that predate the inclusion of tumour depth. In this series, we retrospectively reviewed clinical and radiological data to update primary tumour to the current standard.

Our results are in accordance with these previous results since the score we used on the decision analysis is based on the risk of occult neck metastasis. Our occult metastasis rate is $27.5 \%$, but no significant difference was seen in disease-specific survival.

\section{Conclusions}

The use of a predictive score to decide on elective neck dissection is reliable. It is a step towards more personalised medicine in which treatment is tailored to suit the patient and not personal preferences or "one size fits all" solutions.

\section{Conflict of interest statement}

None declared. 


\section{References}

1 Kowalski LP, Medina JE. Nodal metastases. Otolaryngol Clin N Am 1998;31:621-37.

2 Castelijns A, van den Brekel MW. Imaging of lymphadenopathy in the neck. Eur Radiol 2002;12:727-38. https://doi.org/10.1007/ s003300101102

3 Furukawa M, Dillon JK, Futran ND, et al. The prevalence of lymph node metastases in clinically NO necks with oral cavity squamous cell carcinoma: is CT good enough for nodal staging? Acta Radiol 2014;55:570-8. https://doi.org/10.1177/0284185113499326

4 Leeflang MM, Bossuyt PM, Irwig L. Diagnostic test accuracy may vary with prevalence: implications for evidence-based diagnosis. J Clin Epidemiol 2009;62:5-12. https://doi.org/10.1016/j.jclinepi.2008.04.007

5 Werning JW, Heard D, Pagano C, et al. Elective neck management of the clinically negative neck by otolaryngologists in patients with oral tongue cancer. Arch Otolaryngol Head Neck Surg 2003;129:838. https://doi.org/10.1001/archotol.129.1.83

6 Dünne AA, Folz BJ, Kuropkat C, et al. Extent of surgical intervention in case of $N O$ neck in head and neck cancer patients: an analysis of data collection of 39 hospitals. Eur Arch Otolaryngol 2004;261:295-303. https://doi.org/10.1007/s00405-003-0680-1

7 Vandenbrouck C, Sancho-Garnier H, Chassagne D, et al. Elective versus therapeutic neck dissection in epidermoid carcinoma of the oral cavity: results of a randomized clinical trial. Cancer 1980;46:38690. https://doi.org/10.1002/1097-0142(19800715)46:2<386::AIDCNCR2820460229>3.0.CO;2-9

8 Fakih AR, Rao RS, Borges AM, et al. Elective versus therapeutic neck dissection in early carcinoma of the oral tongue. Am J Surg 1989;158:309-13. https://doi.org/10.1016/0002-9610(89)90122-0

9 Yuen AP, Ho CM, Chow TL, et al. Prospective randomized study of selective neck dissection versus observation for NO neck of early tongue carcinoma. Head Neck 2009;31:765-72. https://doi. org/10.1002/hed.21033

10 Dias FL, Kligerman J, Matos de Sá G, et al. Elective neck dissection versus observation in stage I squamous cell carcinomas of the tongue and floor of mouth. Otolaryngol Head Neck Surg 2001;125:23-9. https://doi.org/10.1067/mhn.2001.116188

11 D'Cruz AK, Vaish R, Kapre N, et al. Elective versus therapeutic neck dissection in node-negative oral cancer. $\mathrm{N}$ Engl J Med 2015;373:521-9. https://doi.org/10.1056/NEJMoa1506007

12 Civantos FJ, Zitsch RP, Schuller DE, et al. Sentinel lymph node biopsy accurately stages the regional lymph nodes for T1-T2 oral squamous cell carcinomas: results of a prospective multi-institutional trial. J Clin Oncol 2010;28:1395-400. https://doi.org/10.1200/ JCO.2008.20.8777

13 Weiss MH, Harrison LB, Isaacs RS. Use of decision analysis in planning a management strategy for the stage NO neck. Arch Otolaryngol Head Neck Surg 1994;120:699-702. https://doi.org/10.1001/ archotol.1994.01880310005001

14 Okura M, Aikawa T, Sawai NY, et al. Decision analysis and treatment threshold in management for the NO neck of the oral cavity carcinoma. Oral Oncol 2009;45:908-11. https://doi.org/10.1016/j. oraloncology.2009.03.013

Received: February 6, 2018 - Accepted: April 10, 2018
15 Lydiatt WM, Patel SG, O'Sullivan B, et al. Head and neck cancers major changes in the American Joint Committee on Cancer eighth edition cancer staging manual. CA Cancer J Clin 2017;67:122-37. https://doi.org/10.3322/caac.21389

16 Vickers AJ, Elkin EB. Decision curve analysis: a novel method for evaluating prediction models. Med Decis Making 2006;26:565-74. https://doi.org/10.1177/0272989X06295361

17 Azur MJ, Stuart EA, Ftangakos C, et al. Multiple imputation by chained equation: what is it and how does it work? Int J Methods Psychiatry Res 2011;20:40-9. https://doi.org/10.1002/mpr.329

18 Tibshirani R. Regression shrinkage and selection via the LASSO. J R Stat Soc B 1996;58:267-88

19 Teymoortash A, Hoch S, Eivazi B, et al. Postoperative morbidity after different types of selective neck dissection. Laryngoscope 2010;120:924-9. https://doi.org/10.1002/lary.20894

20 Stuckensen T, Kovács AF, Adams S, et al. Staging of the neck in patients with oral cavity squamous cell carcinoma: a prospective comparison of PET, ultrasound, CT and MRI. J Craniomaxillofac Surg 2000;28:319-24. https://doi.org/10.1054/jcms.2000.0172

21 Liao LJ, Lo WC, Hsu WL, et al. Detection of cervical lymph node metastasis in head and neck cancer patients with clinically NO neck - a meta-analysis comparing different imaging techniques. BMC Cancer 2012;12:236. https://doi.org/10.1186/1471-2407-12236

22 Moritz JD, Ludwig A, Oestmann JW. Contrast-enhanced color Doppler sonography for evaluation of enlarged cervical lymph nodes in head and neck tumors. AJR 2000;174:1279-84. https://doi. org/10.2214/ajr.174.5.1741279

23 Zenk J, Bozzato A, Steinhart H, et al. Metastatic and inflammatory cervical lymph nodes as analysed by contrast-enhanced color-coded Doppler ultrasonography: quantitative dynamic perfusion patterns and histopathologic correlation. Ann Otol Rhinol Laryngol 2005;114:43-7. https://doi.org/10.1177/000348940511400108

24 Chatzistefanou I, Lubek J, Markou K, et al. The role of neck dissection and postoperative adjuvant radiotherapy in cNO patients with PNI-positive squamous cell carcinoma of the oral cavity. Oral Oncol 2014;50:753-8. https://doi.org/10.1016/j.oraloncology.2014.05.005

25 Yeh CF, Li WY, Yang MH, et al. Neck observation is appropriate in T1-2, cNO oral squamous cell carcinoma without perineural invasion or lymphovascular invasion. Oral Oncol 2014;50:857-62. https://doi.org/10.1016/j.oraloncology.2014.06.002

26 Liu TR, Chen FJ, Yang AK, et al. Elective neck dissection in clinical stage I squamous cell carcinoma of the tongue: does it improve regional control or survival time? Oral Oncol 2011;47:136-41. https:// doi.org/10.1016/j.oraloncology.2010.11.018

27 Peng KA, Chu AC, Lai C, et al. Is there a role for neck dissection in T1 oral tongue squamous cell carcinoma? The UCLA experience. Am J Otolaryngol 2014;35:741-6. https://doi.org/10.1016/j. amjoto.2014.06.019

28 Abu-Ghanem S, Yehuda M, Carmel NN, et al. Elective neck dissection vs observation in early-stage squamous cell carcinoma of the oral tongue with no clinically apparent lymph node metastasis in the neck. A systematic review and meta-analysis. JAMA Otolaryngol Head Neck Surh 2016;142:857-65. https://doi.org/10.1001/jamaoto.2016.1281

\footnotetext{
How to cite this article: Köhler HF, Kowalski LP. A decision analysis model for elective neck dissection in patients with cT1-2 cNO oral squamous cell carcinoma. Acta Otorhinolaryngol Ital 2019;39:374-380. https://doi.org/10.14639/0392-100X-2101
}

Address for correspondence: Hugo Fontan Köhler, rua Professor Antônio Prudente 213, São Paulo, Brazil. E-mail: hkohler75@uol.com.br This is an open access article distributed in accordance with the Creative Commons Attribution Non Commercial (CC BY-NC 4.0) license, which permits others to distribute, remix, adapt, build upon this work non-commercially, and license their derivative works on different terms, provided the original work is properly cited, appropriate credit is given, any changes made indicated, and the use is non-commercial. See: http://creativecommons.org/licenses/by-nc/4.0/. 